\title{
VISITAS DE ESCOLAS E UNIVERSIDADES À ÁREA DE PROTEÇÃO AMBIENTAL DE GUAPIMIRIM (RJ), COM ÊNFASE NOS ANOS DE 2011 E 2012
}

\author{
Juliana Cristina Fukuda ${ }^{1}$ \\ Andressa Pieroni Santana ${ }^{1}$ \\ Zuth da Silva Coelho' \\ Maurício Barbosa Muniz ${ }^{1}$ \\ Tatiana Figueira de Mello ${ }^{1}$ \\ Klinton Vieira Senra ${ }^{1}$ \\ Breno Herrera da Silva Coelho ${ }^{2}$ \\ Adilson Fernandes ${ }^{1}$ \\ Alaildo Malafaia ${ }^{1}$
}

\section{Resumo}

Criada em 1984, a Área de Proteção Ambiental (APA) Guapimirim abrange 14 mil ha de manguezais, área marinha, propriedades rurais e adensamentos urbanos nos municípios de São Gonçalo, Magé, Guapimirim e Itaboraí, no recôncavo da Baía de Guanabara/RJ. A Estação Ecológica (ESEC) Guanabara, criada em 2006, fica no interior da APA Guapimirim e abrange cerca de 2 mil ha. A APA Guapimirim é bastante utilizada para fins de lazer, especialmente nos rios e na orla da Baía de Guanabara, mas o monitoramento quanto a esse uso não é realizado. Na sede administrativa existe controle sobre ao uso, pois os visitantes passam por ali, antes de serem conduzidos a outros pontos da UC. A sede da APA Guapimirim recebeu 2566 visitantes nos anos de 2011 e 2012. A maior parte dessas visitas (52,5\%) é realizada por escolas e universidades. Em 2011 foram realizadas 17 visitas escolares, totalizando 540 estudantes; em 2012 foram 16 visitas, totalizando 640 alunos. Desses estudantes, $51,1 \%$ são de nível superior e $85,7 \%$ provém de universidades públicas. Com a instalação de uma trilha planejada para 2014, cujo acesso será facilitado por meio de uma passarela suspensa no manguezal, pretende-se aumentar a quantidade e a qualidade das visitas.

Palavras-chave: APA Guapimirim, manguezal, visitação pública, escolas, universidades

\begin{abstract}
Founded in 1984, Guapimirim Environmental Protected Area (EPA) covers 14,000 ha of mangroves, marine area, farms and urban concentrations in the cities of São Gonçalo, Itaboraí, Magé and Guapimirim in the back borders of Guanabara Bay. Guanabara Ecological Station (ESEC) was established in 2006, is within Guapimirim EPA and covers about 2000 ha. Guapimirim EPA is widely used for leisure purposes, especially in the rivers and on Guanabara Bay coast, but monitoring this use is not performed. Yet, the headquarter has great control on the use. It is the first place where visitors are received, being later taken to other points of protected area. Guapimirim EPA headquarter received 2566 visitors in the years 2011 and 2012. Considering each visit as an event, about $52.5 \%$ of these visits are made by

\footnotetext{
1 Núcleo de Gestão Integrada da APA Guapimirim e da Estação Ecológica da Guanabara - Instituto Chico Mendes de Conservação da Biodiversidade (ICMBio). BR-493, km 12,8, Guapimirim, RJ, CEP 25940-000. http://www.icmbio.gov.br/apaguapimirim. E-mail: juliana.fukuda@icmbio.gov.br

2 Parque Nacional da Serra dos Órgãos - ICMBio
} 
schools and universities. In 2011, 17 school visits were conducted, totaling 540 students, in 2012 there were 16 visits totaling 640 students. Approximately $51.1 \%$ of these students are undergraduates and $85.7 \%$ of universities visits are made by public institutions. After the installation of a trail with easy access which will include a walkway in mangrove, what is planned for 2014, the quantity and quality of visits is expected to increase.

Keywords: Guapimirim Environmental Protected Area; mangrove; public visitation; schools; universities

\section{Introdução}

A Área de Proteção Ambiental (APA) Guapimirim foi criada em 1984 como a primeira unidade de conservação (UC) brasileira com objetivo explícito de conservação dos manguezais. Possui extensão de cerca de 14 mil hectares(ha), abrangendo manguezais, área marinha, poucas propriedade rurais e pequenos adensamentos urbanos nos municípios de São Gonçalo, Itaboraí, Guapimirim e Magé, estando inserida em uma das maiores metrópoles da América do Sul. Por este motivo, a área tem sido continuamente ameaçada pelo crescimento urbano dos municípios onde se localiza, onde as principais ameaças diretas são aterros, invasão por habitações irregulares, despejos de efluentes domésticos e agrícolas sem tratamento, vazadouros de lixo, poluição por óleo, desmatamentos, queimadas.

A proteção de ecossistemas de grande relevância ambiental é reforçada pela existência da Estação Ecológica (ESEC) da Guanabara, criada em 2006, com cerca de 2 mil ha, localizada na porção central da APA (Figura 01). Essas duas unidades de conservação (UCs) possuem gestão compartilhada, otimizando recursos e são administradas pelo governo federal, através do Instituto Chico Mendes de Conservação da Biodiversidade (ICMBio), autarquia ligada ao Ministério do Meio Ambiente.

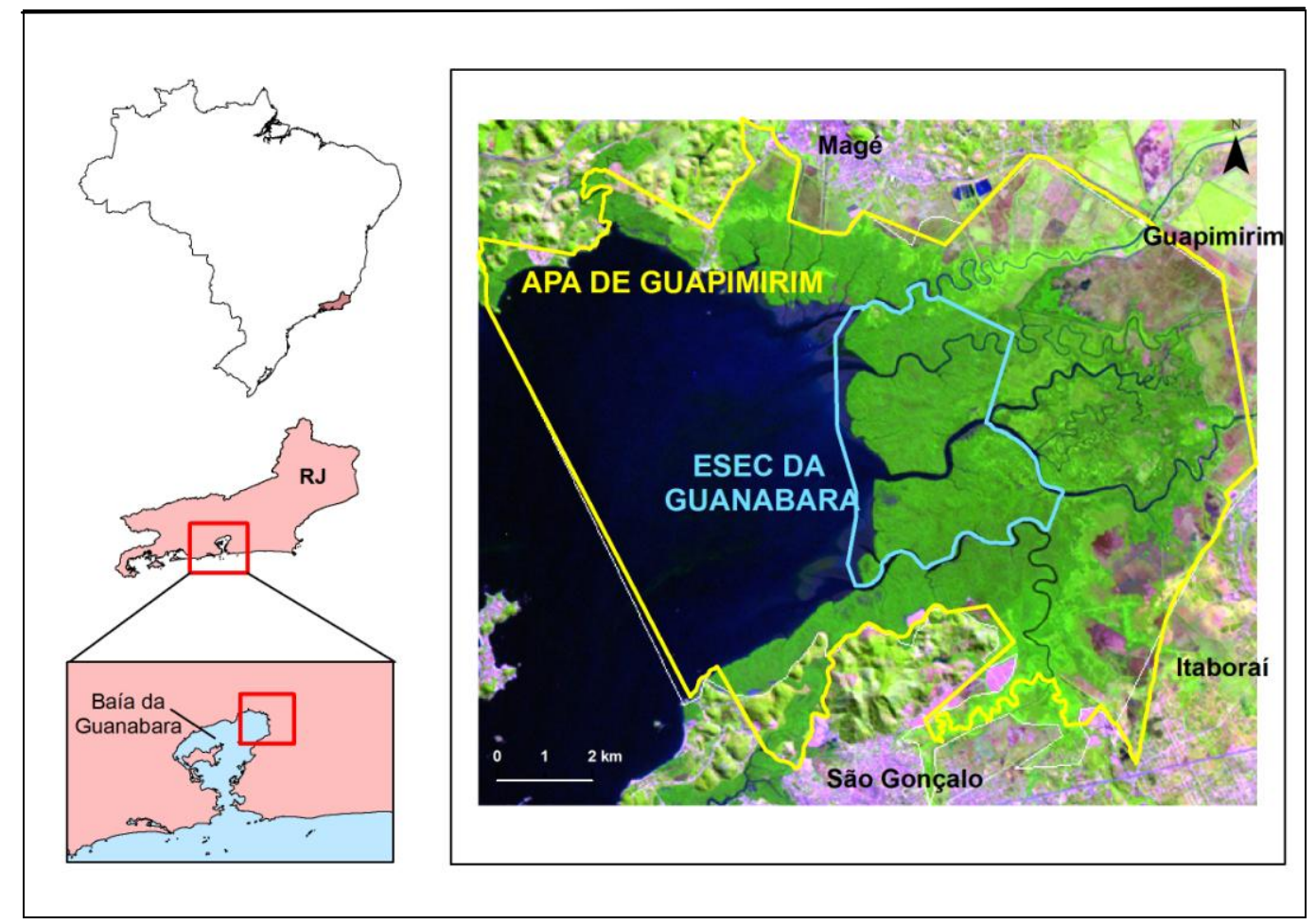

Figura 01. Localização da APA Guapimirim e ESEC Guanabara 
Conforme disposto na lei que instituiu o Sistema Nacional de Unidades de Conservação (BRASIL, 2000), alguns dos objetivos diretos das UCs são: favorecer condições e promover a educação e interpretação ambiental, a recreação em contato com a natureza e o turismo ecológico, bem como proporcionar meios e incentivos para atividades de pesquisa científica, estudos e monitoramento ambiental.

De acordo com as "Diretrizes para Visitação em Unidades de Conservação", documento divulgado pelo Ministério do Meio Ambiente, "a visitação é instrumento essencial para aproximar a sociedade da natureza, despertar a consciência da importância da conservação dos ambientes e processo naturais, independentemente da atividade que está praticando na Unidade de Conservação" (MMA, 2006).

Existem diversas atividades de uso público que são realizadas rotineiramente na APA Guapimirim, como: visitas por estudantes de escolas e universidades, visitas por ONGs ou outros grupos organizados, visitas de particulares para lazer nos rios ou para passeios de barco ou para pesca esportiva, além de captação de imagens e informação para reportagens. Conforme indicado no plano de manejo da unidade (IBAMA, 2004), há potencial para atividades de observação de aves e de visitação aos monumentos históricos da região, mas que ainda não têm despertado tanto interesse público até o momento.

Por se tratar de uma UC de uso sustentável com moradores e atividades diversas (criação de animais, serviços, comércio e outros) numa área relativamente extensa, é difícil quantificar os diferentes usos que acontecem na APA Guapimirim. Pretende-se, ainda em 2013, produzir e fixar placas informativas em locais de maior acesso além da utilização de um caderno de registros para quantificação da visitação à UC. Existe uma sede administrativa ${ }^{3}$ da APA que exerce controle dos usos e acessos, sendo o local onde os visitantes são recebidos para, posteriormente, se deslocarem para outros pontos da UC.

O objetivo geral deste trabalho é apresentar informações sobre o uso público na APA Guapimirim, tendo como referência as visitas ocorridas nos anos de 2011 e 2012. Especificamente, pretende-se apresentar dados sobre o movimento de estudantes na UC, e trazer a proposta de trilha que deverá ser implementada até 2014.

O trabalho foi realizado através da sistematização dos registros de visitas nos anos supracitados e da explanação da proposta de implementação de uma trilha que inclui uma passarela suspensa sobre o manguezal.

\section{O perfil das visitas à APA Guapimirim}

A sede da APA Guapimirim recebeu 2.566 visitantes nos anos de 2011 e 2012. Nesta contagem não foram incluídas as pessoas que se dirigem à sede para fins de licenciamento, como os empreendedores interessados em realizar alguma atividade na UC, ou de convocados a comparecer por notificação ou por auto de infração, ou qualquer outra rotina administrativa (correios, entrega de materiais, etc).

\footnotetext{
${ }^{3}$ Localizada à BR 493 km 12,8, Município de Guapimirim, RJ
} 
Conforme os dados da Figura 02, cerca de 52,5\% (31) dos eventos ${ }^{4}$ de visita à APA Guapimirim eram oriundos de escolas e universidades, seguido pela mídia $(9-15,3 \%)$ e conselheiros e convidados pelo conselho gestor (7 - 11,9\%).

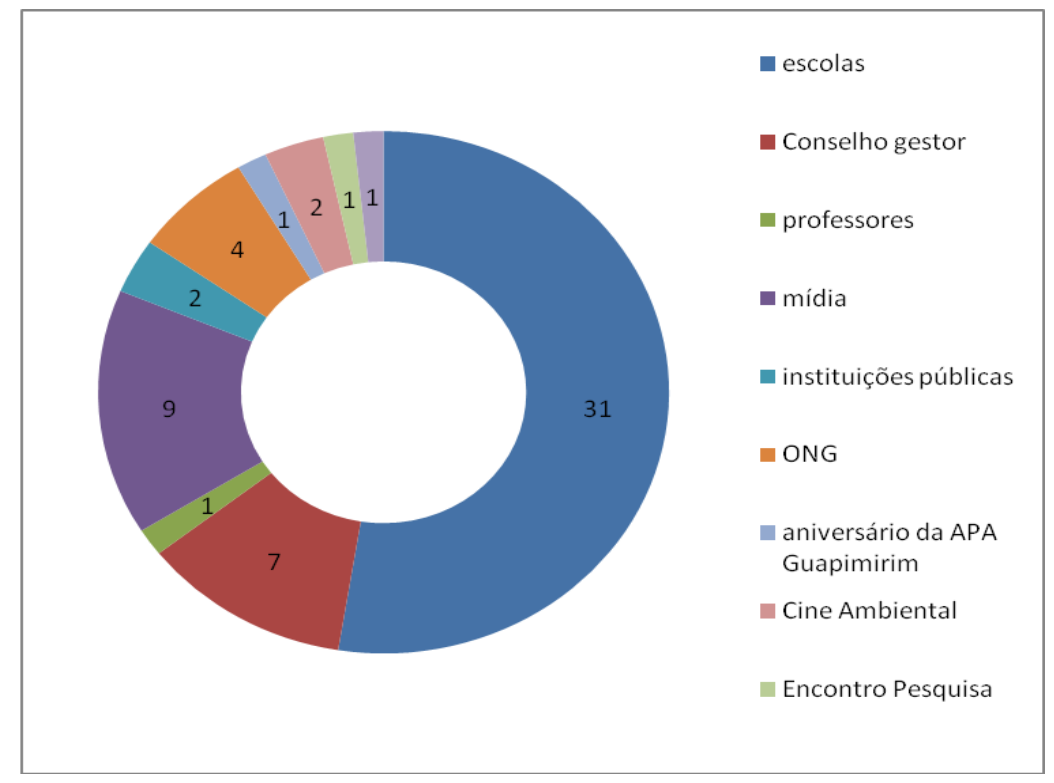

Figura 02. Motivos das visitas à APA, considerando cada visita como um evento

\section{As visitas de estudantes de escolas e universidades}

A APA Guapimirim é procurada para visitas organizadas principalmente por estudantes escolas e universidades. A divulgação da atividade é feita principalmente através do site da UC (www.icmbio.gov.br/apaguapimirim). O agendamento prévio é feito via telefone ou correio eletrônico, quando se combina com o responsável os detalhes da visita.

Geralmente, a visita inicia-se no auditório da sede da UC, onde é realizada uma palestra com a finalidade de enfocar os diversos temas concernentes ao processo de gestão ambiental, principalmente conteúdos sobre a ecologia do manguezal e a sua importância. Após as palestras, os participantes são levados para as atividades de campo a fim de fortalecer o processo educativo.

Quando há a possibilidade de a instituição de ensino ou de os alunos custearem a contratação de serviço de condução embarcada, a atividade de campo se desenvolve através de roteiros guiados por meio de embarcações. Nesse caso, o grupo contrata diretamente os serviços de transporte junto a uma associação ou a uma cooperativa da região, cujos condutores foram capacitados para essas atividades sob supervisão de segurança e de procedimentos da equipe de servidores do ICMBio. Os estudantes percorrem por cerca de uma hora e meia os rios Guapimirim e Guaraí, podendo chegar até a Baía de Guanabara quando as condições climáticas estão adequadas à navegação. Os estudantes fazem o percurso por cerca de uma hora e meia nos rios Guapimirim e Guaraí, chegando até a Baía de Guanabara, dependendo das condições climáticas favoráveis à navegação. Devido ao custo de

\footnotetext{
${ }^{4}$ Cada evento considerado é independente do número de pessoas.
} 
cerca de $\mathrm{R} \$ 60,00 /$ pessoa, esse tipo de visitação costuma ser realizado por turmas de graduação e pós-graduação.

Para os alunos de Educação Infantil, Educação Fundamental e Ensino Médio, o grupo é conduzido via terrestre, no próprio ônibus que os levou à sede da APA Guapimirim, até o bairro de Piedade ou do Remanso, no município de Magé. Nesses locais, à beira da Baía de Guanabara, os alunos são conduzidos por trilhas por áreas de manguezal alterado.

Em 2011 ocorreram 17 visitas escolares, totalizando 540 estudantes e em 2012, foram 16 visitas com 640 alunos. A quantidade de instituições formais de ensino que tiveram alunos em visita à UC está representada na Figura 03, e o total de pessoas, na Figura 04.

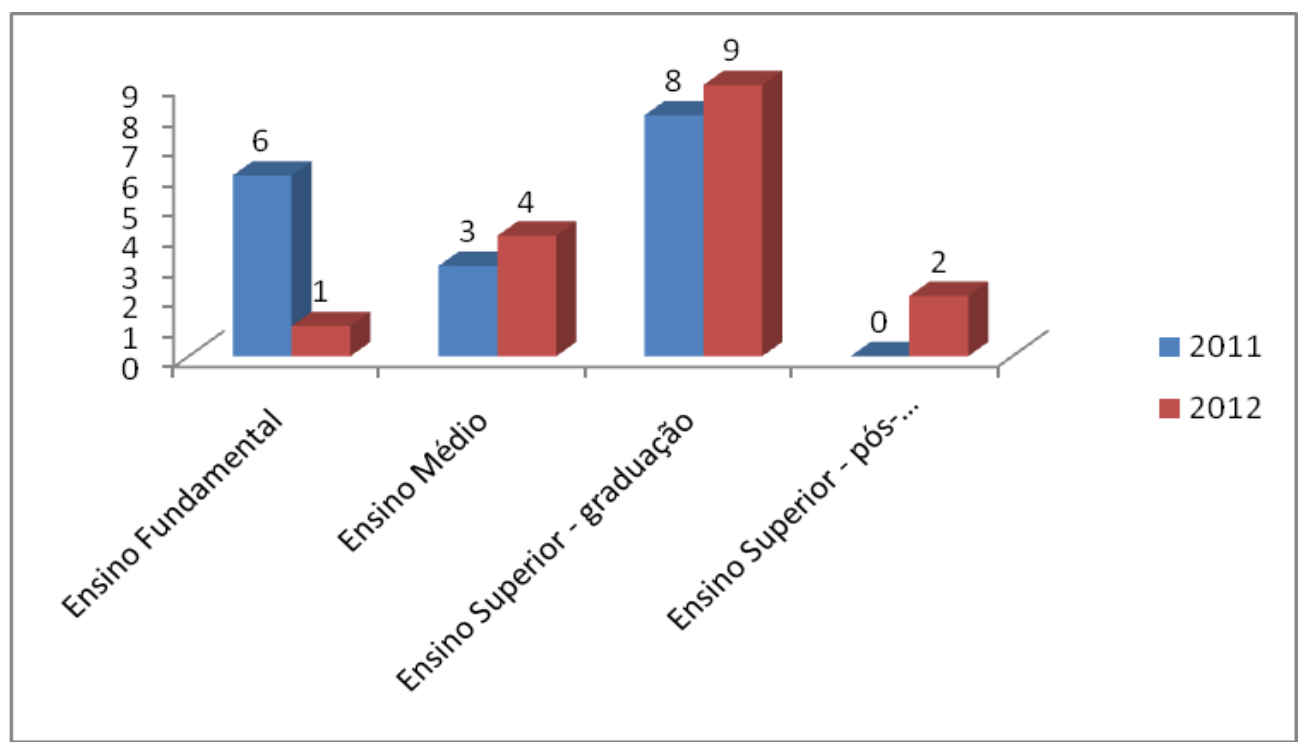

Figura 03. Número de instituições de ensino cujos alunos e professores visitaram a APA

Guapimirim, de acordo com grau de ensino e ano.

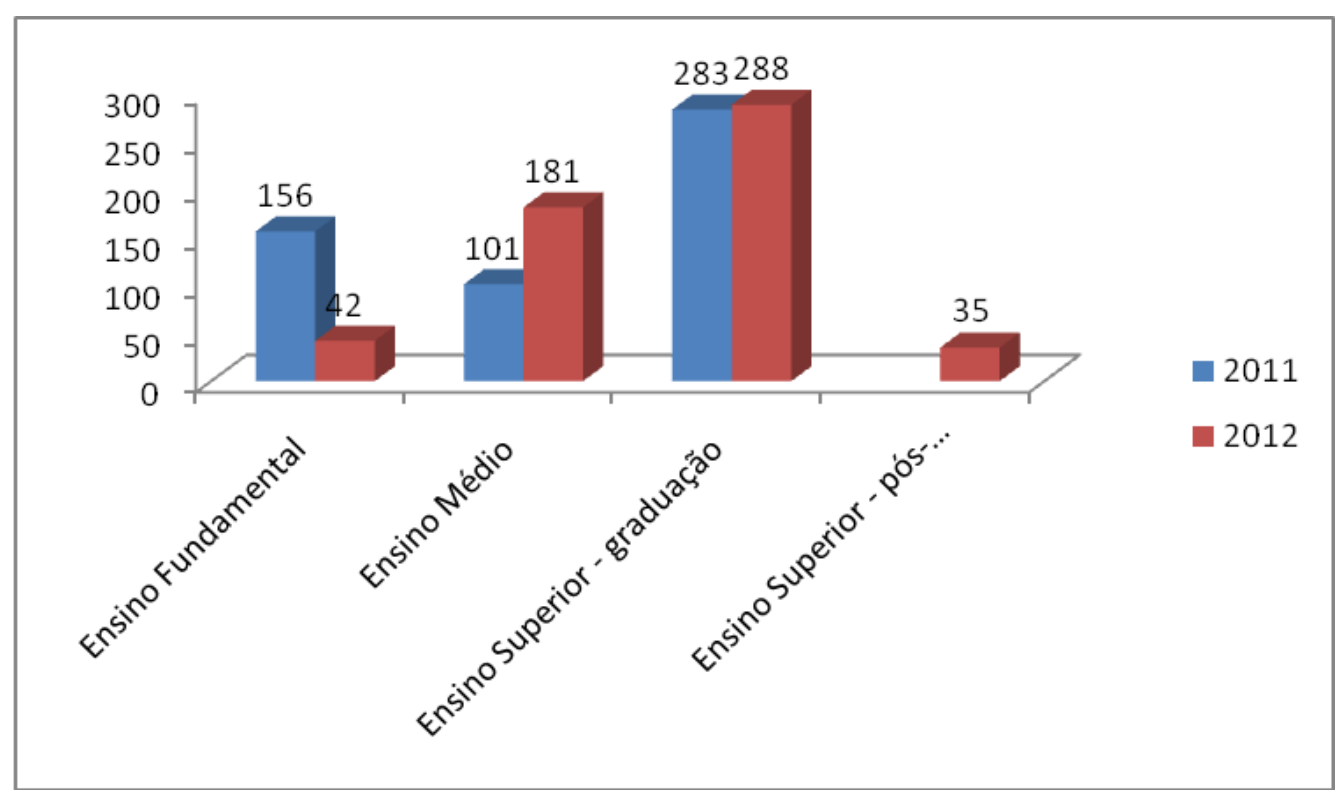

Figura 04. Número de estudantes e professores que visitaram a APA Guapimirim, de acordo com grau de ensino e ano 
Através dos quadros acima percebem-se que as visitas escolares são feitas predominantemente por turmas de graduação, seguidas por turmas de Ensino Médio, Ensino Fundamental e pós-graduação. Nos anos de 2011 e 2012 não foram feitas visitas por nenhuma turma de Educação Infantil. Podem-se explicar os resultados da seguinte forma:

a) os cursos superiores, em geral, têm maneiras de custear a visita embarcada, e isso possibilita aos estudantes visitar os manguezais mais conservados da Baía de Guanabara. Para os demais segmentos, como as áreas de manguezal visitadas não são tão exuberantes e o deslocamento é difícil dentro dessas áreas, talvez haja preferência por outras áreas de manguezal, como o do Projeto Mangue Vivo, da ONG Onda Azul, recentemente abrangido pelo Parque Natural Municipal de Barão de Mauá;

b) nas turmas de cursos superiores, o transporte até a sede da APA Guapimirim / ESEC Guanabara é feito com ônibus da própria instituição. Para as escolas públicas de nível fundamental e médio, há poucos ônibus disponíveis pela prefeitura para realizar esse tipo de transporte, o que foi citado por professores durante seminários realizados junto a educadores das escolas da região em 2011 (FUKUDA et al., 2011).

Dentre as turmas de ensino superior, a procura é predominantemente de instituições públicas (Figura 05). Nota-se também que são os mesmos docentes que trazem suas turmas todos os anos, indicando que as visitas têm sido aprovadas.

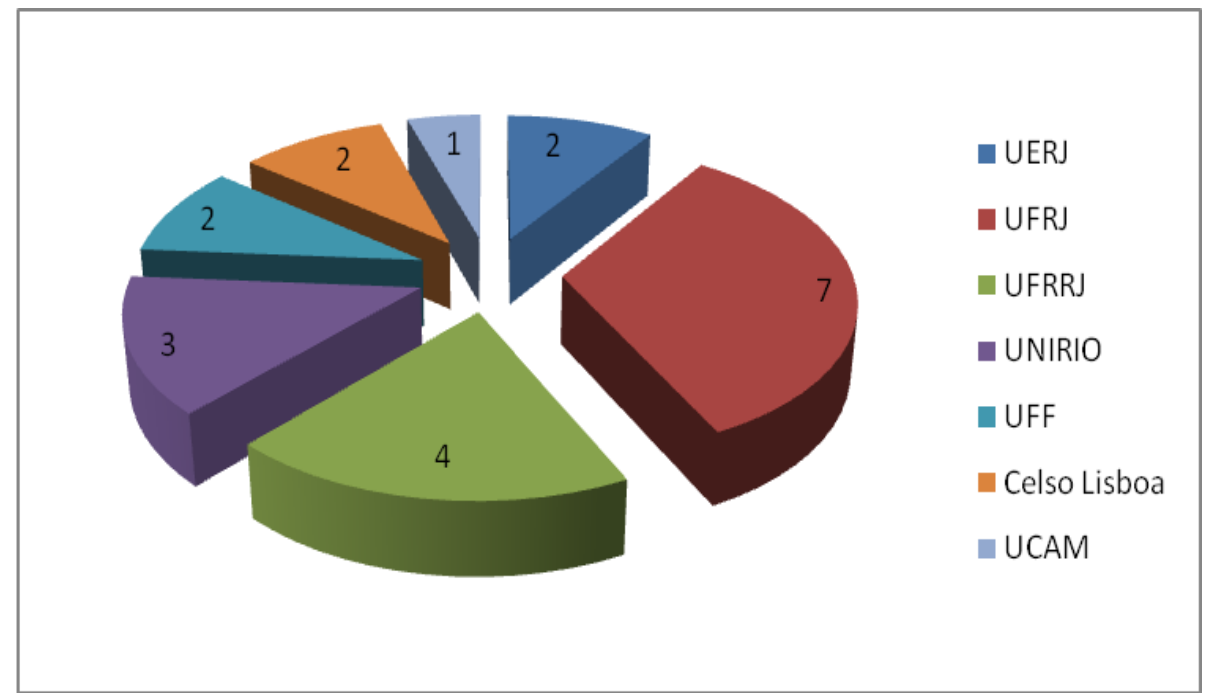

Figura 05. Número de visitas realizadas por instituições de ensino superior ${ }^{5}$ na APA Guapimirim (2011 e 2012).

A partir de 2013 a palestra inicial será acompanhada de uma atividade lúdica sobre algum tema ambiental, de acordo com a idade dos estudantes. Também tem sido oferecida aos professores a possibilidade de preparo de mudas nativas para que os estudantes levem para casa. Pode-se, também, realizar um plantio à margem do rio Guapimirim utilizando-se mudas

\footnotetext{
${ }^{5}$ UERJ - Universidade do Estado do Rio de Janeiro; UFRJ - Universidade Federal do Rio de Janeiro; UFRRJ Universidade Federal Rural do Rio de Janeiro; UNIRIO - Universidade Federal do Estado do Rio de Janeiro; UFF - Universidade Federal Fluminense; Celso Lisboa - Centro Universitário Celso Lisboa; UCAM Universidade Cândido Mendes
} 
do viveiro da APA Guapimirim.

\section{A trilha terrestre}

Até o final de 2013 deverá ser elaborado o projeto executivo de uma trilha cujo início fica a cerca de cem metros da sede da APA Guapimirim / ESEC Guanabara, viabilizando o acesso a pé dos visitantes. Isso aumentará a qualidade da visitação e, consequentemente, a possibilidade de sensibilização sobre o ambiente de manguezal. A trilha será acessível à cadeirantes, possibilitando a esse grupo a participar de uma experiência diferenciada.

O primeiro trecho da trilha passará por uma área de mata ciliar em recuperação, onde estão sendo plantadas mudas nativas há três anos. O segundo trecho fica em área onde está sendo recuperado um setor do manguezal, chegando a um local de vegetação mais densa onde haverá acesso por meio de uma passarela suspensa de trajeto circular, até se chegar num mirante. A passarela também será acessível via fluvial. Os dois primeiros trechos juntos terão extensão de 3500 metros, e a passarela suspensa, de 1200 metros. Espera-se que até o final de 2014 a trilha e a passarela estejam implementadas.

\section{Conclusões}

A APA Guapimirim é utilizada pela sociedade para diversos fins, como pesca amadora, contemplação e fins educacionais, cumprindo uma das funções fundamentais das UCs, que é de aproximar a sociedade da natureza.

Devido à extensão da área e ao fácil acesso por diversos pontos, a visitação só é controlada na sua sede. Nela, prevalece o público estudantil oriundo de escolas do ensino fundamental, médio e superior, que visitam a área após agendamento. Entre os visitantes, a maioria é formada de alunos de graduação e de instituições públicas de nível superior. Até hoje não houve visita de nenhuma turma de educação infantil. As turmas de nível superior costumam fazer visitas embarcadas, o que não ocorre com os alunos de outros níveis, devido ao custo para contratação do serviço de condução de embarcação.

Está sendo planejada a instalação de uma trilha que incluirá uma passarela suspensa sobre o manguezal, devendo ficar pronta até o final de 2014. Com esse atrativo, espera-se que a visitação de crianças da educação básica e de outras pessoas, inclusive de deficientes físicos, se torne mais interessante e acessível.

\section{Referências bibliográficas}

BRASIL. LEI N. ${ }^{\circ} 9.985$, de 18 de julho de 2000. Regulamenta o art. 225, $\S 1^{\circ}$, incisos I, II, III e VII da Constituição Federal, institui o Sistema Nacional de Unidades de Conservação da Natureza e dá outras providências.

IBAMA( Instituto Brasileiro do Meio Ambiente e dos Recursos Naturais Renováveis). Plano de Manejo da Área de Proteção Ambiental de Guapimirim. IBAMA, 2004.

ICMBIO. Instituto Chico Mendes de Conservação da Biodiversidade. Instrução Normativa N. o 27, de 04 de julho de 2012. Definir critérios para credenciamento e autorização dos serviços de condução de visitantes com fins recreacionais, educacionais ou de pesquisa, nas áreas de 
domínio público da Área de Proteção Ambiental de Guapimirim, bem como a condução de visitantes com fins educacionais ou de pesquisa na Estação Ecológica da Guanabara.

FUKUDA, J. C. et al. Diagnóstico sobre os Professores nas Escolas da Região da Área de Proteção Ambiental de Guapimirim (RJ) em relação á Educação Ambiental. In: SEMINÁRIO BRASILEIRO SOBRE ÁREAS PROTEGIDAS E INCLUSÃ̃O SOCIAL, 5., 2011, Manaus. Anais eletrônicos... Manaus, 2011.

Ministério do Meio Ambiente. Diretrizes para Visitação em Unidades de Conservação. Brasília, DF, 2006. 